\title{
L'Afrique du Sud dix ans après
}

Philippe Guillaume, Nicolas Péjout, Aurelia Wa Kwabe-Segatti (éds),

L'Afrique du Sud dix ans après. Transition accomplie ?, Paris, Karthala, 2004, 361 p.

\section{Philippe Gervais-Lambony}

\section{(2penEdition}

\section{Journals}

Édition électronique

URL : http://journals.openedition.org/transcontinentales/1448

DOI : $10.4000 /$ transcontinentales. 1448

ISBN : 978-2-8218-1408-0

ISSN : 1775-397X

Éditeur

Editions de la maison des sciences de l'homme

Édition imprimée

Date de publication : 30 juin 2006

Pagination : 173-174

ISBN : 2200-92169-1

ISSN : 1950-1684

Référence électronique

Philippe Gervais-Lambony, «L'Afrique du Sud dix ans après », Transcontinentales [En ligne], 2 | 2006, document 11, mis en ligne le 15 décembre 2012, consulté le 25 septembre 2020. URL : http:// journals.openedition.org/transcontinentales/1448; DOI : https://doi.org/10.4000/transcontinentales. 1448

Ce document a été généré automatiquement le 25 septembre 2020

Tous droits réservés 


\section{L'Afrique du Sud dix ans après}

Philippe Guillaume, Nicolas Péjout, Aurelia Wa Kwabe-Segatti (éds), L'Afrique du Sud dix ans après. Transition accomplie?, Paris, Karthala, $2004,361 \mathrm{p}$.

Philippe Gervais-Lambony

\section{RÉFÉRENCE}

Philippe Guillaume, Nicolas Péjout, Aurelia Wa Kwabe-Segatti (éds), L'Afrique du Sud dix ans après. Transition accomplie ?, Paris, Karthala, 2004, 361 p.

1 Ce volume, qui réunit douze textes sur la période de transition de l'Afrique du Sud, est un pari gagné : celui de cibler une période précise de l'histoire récente de ce pays et de donner une cohérence à des regards sur des objets très divers. Dix ans après les premières élections libres en Afrique du Sud, il fait le point sur une transition encore inachevée.

2 Pas de description du passé d'apartheid de l'Afrique du Sud donc, mais l'analyse d'une décennie de transition. Cela pose d'emblée une question quant à la rupture qu'a constituée le changement de régime après l'élection de Nelson Mandela à la présidence de la république en 1994. Or, les textes réunis ici démontrent que cette rupture est relative dans bien des domaines, par exemple en ce qui concerne les politiques sur l'immigration, l'éducation ou la réforme foncière. Bien des changements sont postérieurs à 1994, et il faut évoquer une autre rupture qui se dessine dès le milieu des années 1990 mais est renforcée surtout après 1997: il s'agit d'une inflexion de la politique économique et des politiques en matière de logement et d'accès au foncier, du passage d'une priorité donnée à l'équité à une primauté de l'efficacité et de la rentabilité qu'en simplifiant on peut qualifier d'orientations de type néo-libérales. La politique de réforme foncière, analysée ici par W. Anseeuw, illustre parfaitement ce choix politique : si dans la période 1994-1999 il s'agissait avant tout de développer une agriculture de subsistance, c'est l'émergence d'une classe d'agriculteurs commerciaux noirs qui est visée depuis 1999. Globalement, le virage politico-économique a été 
effectué avec succès (et explique les $5 \%$ de croissance annuelle de l'économie sudafricaine) mais il a pour conséquence le maintien, voire le renforcement, des inégalités héritées (il n'est sans doute pas inutile de rappeler que, d'après les chiffres du PNUD, l'Indice de développement humain de l'Afrique du Sud, après avoir augmenté jusqu'en 1995, diminue depuis).

3 Il est frappant de constater combien les textes réunis ici, écrits par une nouvelle génération de chercheurs pour la plupart francophones - c'est en soit une réussite du livre que de démontrer ce dynamisme, soutenu par l'Institut français d'Afrique du Sud créé en 1994 -, convergent sur cette question des rythmes du changement. De nombreuses disciplines de sciences sociales sont représentées: sociologie, anthropologie, géographie, sciences politiques, histoire, économie. Les champs couverts sont amples, des questions rurales aux problèmes urbains, de l'émergence d'élites politiques nouvelles aux politiques du logement (le chapitre rédigé par M. Morange sur cette question est particulièrement démonstratif) ou de l'éducation, des évolutions de la littérature sud-africaine aux questions liées à l'émergence de nouvelles identités communautaires (le cas de l'émergence d'une identité Khoesan permet une relecture très originale de cette question). Le livre se clôt, et cela se justifie parfaitement, par un excellent texte sur la question du Sida, défi majeur pour l'Afrique du Sud d'aujourd'hui, et au sujet duquel est parfaitement démontrée l'imbrication des questions politiques, identitaires, économiques et sociales. L'ensemble de l'ouvrage est structuré en quatre grandes parties: reconfiguration du pouvoir, recomposition des territoires, restructuration de la connaissance, reconstruction de soi et du rapport à l'autre. Ajoutons que cette collection de textes est complétée par un glossaire et, surtout, par une très utile « webliographie ».

4 Au total, cet ouvrage est important parce que parfaitement complémentaire de perspectives sur le plus long terme sur l'Afrique du Sud. Il offre aussi un apport non négligeable à la réflexion générale non seulement sur les transitions politiques dans les pays du Sud, mais aussi sur les notions de justice sociale et d'équité : c'est bien un balancement permanent entre désir d'équité d'une part, volonté d'efficience économique d'autre part, qui explique les ambiguïtés actuelles de la société sudafricaine.

\section{AUTEURS}

\section{PHILIPPE GERVAIS-LAMBONY}

Université de Paris 10-Nanterre, et Institut universitaire de France 